\title{
Penerapan Teknik Empat Mallet Pada Lagu Tambourin Paraphrase Untuk Solo Marimba Karya Keiko Abe
}

\author{
Ridhlo Gusti Pradana ${ }^{1}$, Agus Salim ${ }^{2}$, YC Budi Santosa ${ }^{3}$ \\ 1, 2, 3 Prodi Musik FSP Isntitut Seni Indonesia Yogyakarta
}

\begin{abstract}
Four-mallet technique is no stranger to the world of music, especially the melodic percussion instruments (definite) such as, marimba, vibraphone. Elaboration in this paper is on the application of four-mallet technique on songs Tambourin Paraprase for Solo Marimba work Keiko Abe.This thesis aims to provide information to the general public and students of ISI in particular regarding the practicing marimba using four techniques mallet.Process application of techniques four mallet on track Tambourin Paraprase for Solo Marimba using various techniques such as traditional, roll, independent roll, shaft mallet, mallet dead and included in the selection mallet. It is important because precisely of these techniques every piece of music especially played marimba result will be better and more alive.
\end{abstract}

KeywordsFour mallet technique; tambourine Paraphrase for Solo Marimba.

\begin{abstract}
Abstrak
Teknik empat mallet sudah tidak asing lagi dalam dunia musik khususnya pada musik perkusi melodis ( definite ) seperti, marimba, vibraphone. Penjabaran dalam karya tulis ini adalah tentang penerapan teknik empat mallet pada lagu Tambourin Paraprase for Solo Marimba karya Keiko Abe.Penulisan tugas akhir ini bertujuan untuk memberikan informasi kepada masyarakat umum dan mahasiswa ISI Yogyakarta khususnya mengenai permainan marimba dengan menggunakan teknik empat mallet.Proses penerapan teknik empat mallet pada lagu Tambourin Paraprase for Solo Marimba menggunakan berbagai teknik seperti, tradisional roll, independen roll, shaft mallet, dead mallet dan termasuk dalam hal pemilihan mallet. Hal itu sangatlah penting karena justru dari teknik tersebut setiap karya musik khususnya marimba yang dimainkan hasilnya akan menjadi lebih baik dan lebih hidup..
\end{abstract}

Kata kunci: Teknik empat mallet; Tambourin Paraprase for Solo Marimba

\section{Pengantar}

Kapasitas musik sebagai bagian dari bidang kesenian, merupakan ungkapan ekspresi dan bentuk komunikasi universal, yang dapat dinikmati oleh semua lapisan masyarakat. Menurut Curt Sachs dalam bukunya yang berjudul The History of Musical Instrument, hadirnya musik pada Zaman primitive tidak berdiri sediri, tetapi musik tersebut selalu berhubungan erat dengan unsur-unsur kepercayaan yang bersifat magis.

Proses perkembangan musik pada Zaman Primitif terus dilakukan, sesuai akal budi dan ilmu pengetahuan manusia dari generasi ke generasi. Seni musik selalu tumbuh dan berkembang subur di dalam masyarakatnya, hal tersebut tidak mungkin terlepas dari faktor-faktor pendukungnya seperti yang dikemukakan Sumaryo, bahwa musik memerlukan beberapa unsur pokok seperti pencipta musik, pemain musik dan public penggemar musik.

Beberapa unsur tersebut saling terkait satu sama lainnya, seorang pencipta musik akan membutuhkan pemain musik, sedangkan karya yang 
dipentaskanmembutuhkan pendengar atau publik pecinta musik. Musik sebagai hasil kreatif imaginatif manusia dalam mewujudkan serta mengekspresikan pengalaman jiwa dan penghayatannya melalui rasa estetis terus berkembang sesuai dengan kontruksi sosial masyarakat pendukungnya.Musik dalam peran sosial masyarakat pada umumnya berfungsi sebagai ritual dan hiburan, untuk mendukung fungsi sosial tersebut musik tidak bisa dilepaskan dari perkembangan instrumen musik, salah satunya adalah instrumen perkusi.

Musik perkusi yang dimaksud adalah musik perkusi barat, yaitu merupakan bentuk permainan musik dengan menggunakan berbagai jenis alat musik yang mana cara memainkannya dengan dipukul. Alat musik perkusi tersebut di bedakan menjadi dua macam yaitu alat perkusi ritmis ( indefinite) antara lain; snare drum, bas drum, tom-tom, conga, bongo, cymbal, piatti, castagnet, cow bell, dan lain sebagainya. Sedangkan alat musik perksi melodis ( definite) antara lain; marimba, vibraphone, xylophone, glocken spiele, chames, timpani dan lain sebagainya. Alat-alat musik perkusi tersebut secara teknik dapat dimainkan secara tunggal ( solo ), dan juga bermain secara bersama ( ansambel atau orkes ). Selanjutnya fokus penelitian ini akan mengangkat instrumen marimba sebagai bagian dari definite percussion.

Marimba merupakan salah satu jenis alat musik perkusi melodis yang masih tergolong jarang dikenal oleh masyarakat umum. Secara teknik, marimba dimainkan dengan menggunakan stick (mallet) baik dengan dua maupun empat mallet. Dalam perkembangannya yaitu pada tahun 1935 di Amerika Serikat, marimba sudah mulai difungsikan baik dalam bentuk komposisi solo maupun dalam formasi orkes.Salah satu bentuk komposisi untuk marimba solo adalah yang berjudul Tambourin Paraphrase for Solo Marimba karya Keiko Abe. Komposisi ini selain memiliki tingkat kesulitan yang cukup tinggi juga terdapat beberapa hal yang menyangkut masalah teknik stiking seperti; dead stroke, shaft mallet, single shaft, doble shaft dan juga banyak menggunakan perubahan sukat seperti; empat per delapan, enam per delapan, Sembilan per enam belas, tiga per empat,enam per enam belas, tujuh per enam belas, lima per enam belas, dua per delapan, serta komposisi tersebut dimainkan dengan menggunakan empat mallet.

Berkaitan dengan hal tersebut betapa pentingkiranya untuk mempelajaridan mendalami demi meningkatkan mutu permainan khususnya dalam teknik permainan marimba dengan menggunakan empat mallet. Penelitian dengan judul Penerapan Teknik Empat Mallet Pada Lagu Tambourin Paraphrase for Solo Marimba Karya Keiko Abe, merupakan salah satu wujud dalam keikutsertaan menambah wawasan dan pengetahuan khususnya dalam permainan marimba.

\section{Pembahasan}

Pada bagian introduksi mulai birama 1-9, menggunakan teknik dead stroke dan shaft mallet dimulai pada birama 1 ketukan ke 2 dengan posisi mallet 1 pada nada $F$, mallet 2 pada nada $C$, mallet 3 pada nada $f$ dan mallet 4 pada nada c, kemudian secara bersamaan dipukul dan kepala mallet ditempelkan pada bilah selama setengah ketukan karena terdapat legato dan pada ketukan ke 4, nada $\mathrm{F}$ dan $\mathrm{C}$ dipukul menggunakan mallet 1 dan 2 karena posisinya berada pada bilah nada rendah sama halnya pada birama 2. Pada birama 3 terdapat shaft mallet pada ketukan ke 1,2 dan 4 tetapi sedikit terdapat perbedaan yaitu untuk ketukan 1 dan 2 posisi mallet 1 dan 4 dipukulkan pada ujung bawah bilah dengan menggunakan tangkai mallet. Posisi tangkai mallet harus sejajar dengan arah kepala 
mallet menghadap posisi 45 derajat dan dipukulkan memanfaatkan kekuatan pantulan secara alami, kemudian untuk ketukan ke 4 posisi mallet sama dengan sebelumnya tetapi hanya dipukul sekali saja dan tidak dipantulkan sama halnya dengan birama 4. Pada birama 4 posisi mallet 1 dan 2 tetap pada kunci $\mathrm{F}$, lalu pada ketukan ke 2 terdapat dead stroke diikuti posisi mallet 3 di nada A. Ritme $1 / 16$ di birama 4 pada kunci $G$ menggunakan posisi mallet 4-3-4-3 karena lebih memungkinkan. Untuk birama 6-9 hanya terdapat pengulangan teknik yang sama dengan sebelumnya.

\section{Notasi 34 : Birama 10-23}

Pada birama 10-23 tersebut diatas adalah introduksi frase 1 dan 2 merupakan pengembangan dari introduksi yang tentu saja berhubungan untuk nanti masuk ke tema selanjutnya. Pada birama 10 posisi mallet 1 dan 2 tetap pada posisi bass atau kunci $F$, lalu untuk notasi pada kunci $G$ posisi mallet 3 lebih dominan untuk memainkan melodi tersebut. Pada birama 11 posisi mallet pada kunci G dimulai dari mallet 4-3-4-3-4-43, sedangkan birama 12 ketukan 4 terdapat tremolo/roll dimainkan mallet 3 dan 4 dengan menggunakan teknik one hand roll hingga birama 13 ketukan ke 3, dan disaat yang bersamaan terdapat dead stroke di ketukan ke 2 birama 11 pada mallet 1 dan 2 . Birama 14 samapai 16 posisi mallet 1 dan 2 pada kunci $\mathrm{F}$ dan terdapat dead stroke pada tiap nada ke 2 dan 3, kemudian pada kunci G terdapat ritmis trio'l dengan posisi mallet 44-3 pada tiap triolnya. Sebenarnya untuk kemungkinan dalam pemilihan numbering atau sticking mallet pada lagu ini cukup fleksibel, artinya ketika kita memainkannya dengan penuh keyakinan dan tentu saja mendapatkatkan kenyamanan, itu semua dapat dicari sendiri asalkan tidak bertabrakan antara mallet satu dengan mallet lain. Untuk birama 17sampai 21 posisi mallet pada kunci $G$ lebih menyesuaikan dengan gerak mallet 1 dan 2, karena posisi mallet 3 dan 4 memungkinkan memainkan melodi pada kunci G. Sukat yang selalu berubah dapat menyebabkan gesekan antara mallet tetapi dengan cara mencermati frase demi frase gesekan tersebut dapat terhindari. Pada birama 22 dan 23 dengan sukat 4/8 terdapat dead stroke pada ketukan ke 2 up beat dengan posisi mallet 1-4 dipukul secara bersama dengan dinamik forte lalu pada birama 23 terdapat decressendo yang artinya melembut

\section{Notasi 35 : Birama 24-35}

Selanjutnya pada birama 24-35 merupakan tema I terdapat penahanan tempo di birama 24 dan 25. Terdapat dead stroke pada mallet 1 dan 2 dengan nada $F$ dan $\mathrm{C}$ dipukul bersama. Kemudian pada mallet 3 dan 4 memainkan melodi pada kunci G, pada ketukan ke-2 up bead terdapat teknik memukulkan tangkai mallet pada tangan kanan dan kiri sejajar dengan dada. Pada ketukan ke-3 terdapat dead stroke dengan mallet 1, 2, 3, dan 4 memukul nada C D F dan A, selanjutnya birama ke-25 terdapat teknik dengan posisi mallet yang sama. Birama 26 sampai 29 tidak terdapat teknik khusus, melainkan posisi mallet searah berlawanan, mallet 1 dan 2 harus stabil karena banyak presisi pada tiap nada, kemudian untuk mallet 3 dan 4 posisi mallet 3 selalu stabil pada nada $C$ sedangkan mallet 4 yang bergerak naik dan turun. Selanjutnya birama 30 dan 31 mempunyai teknik posisi mallet yang sama yaitu pada birama 24 dan 25. Pada birama 32 hingga 35 juga mempunyai teknik posisi mallet yang sama dengan birama 26 hingga 29.

\section{Notasi 36 : Birama 36-51}

Birama 36-51 merupakan bagian dari pengembangan tema I, birama 36-41 merupakan alternativ, artinya boleh tidak dimainkan apabila jumlah oktaf pada 
marimba tidak mencukupi karena sebenarnya dalam lagu Tambourin Paraphrase for Solo Marimba menggunakan marimba jenis Grand dengan jumlah 5 oktaf. Teknik yang dipakai hanya posisi numbering mallet dan sticking yang harus stabil, contoh pada birama 36-37, mallet 1 dan 2 memukul nada $\mathrm{F}$ dan $\mathrm{A}$, sedangkan mallet 4 pada nada $\mathrm{C}$ karena mallet 4 merupakan pegangan yang paling kuat ditangan kanan sehingga memudah bermain dengan stabil, hal itu juga berlaku pada birama berikutnya hingga birama 43. Hal tersebut memungkinkan untuk posisi mallet disesuaikan dengan melihat bahwa posisi mallet tersebut mendukung pergerakan pada teknik di dalam lagu ini. Pada birama 44-47 terdapat aksen pada tiap ketukan pertama dengan dinamik forte, pada birama ini sangat kuat tekanan pukulannya walaupun diketukan ke 2 up beat terdapat shaft mallet dan berlanjut dead stroke di ketukan ke 4 .

Pada birama ini memiliki posisi yang sangat sulit karena terdapat tenik shaft mallet dan dead stroke sehingga posisi mallet harus stabil, justru posisi gestur tubuh lah yang sangat membantu dalam menjadikan posisi mallet menjadi stabil. Pada birama selanjutnya yaitu 46 dan 47 terdapat dead stroke dengan posisi mallet agak rumit karena terdapat nada yang naik dengan setengan laras. Selanjutkan teknik memukulkan tangkai mallet antara kanan dan kiri, hal ini perlu ketepatan dalam mengeksekusi posisi mallet dengan nada yang dimainkan. Untuk birama 58-51 memiliki penjelasan yang sama dengan pengulasan sebelumnya, dan intinya ketika mendapatkan teknik yang sulit dalam lagu ini gestur tubuh juga berperan penting dalam mendukung pergerakan posisi mallet 1,2,3 dan 4 sehingga dapat diperoleh hasil suara yang indah.

Notasi 37 : Birama 52-59
Pada birama 52-59 terdapat pergerakan posisi mallet yang agak rumit, karena melodi pada kunci $G$ posisi mallet 3 dan 4 melakukan sistem buka dan tutup mallet dengan cepat sehingga butuh genggaman yang kuat pada bagian ini agar mallet tidak terlepas dari pegangan pemain. Posisi mallet 1 dan 2 tetap pada kunci $F$ dan terdapat tekanan/accent pada ketukan 1 dan 2 up beat yang membuat pemain harus sedikit emosi pada bagian ini. Adapun pada birama 56 terdapat dinamik piano, berbeda dengan frase sebelumnmya yang menggunakan dinamik fortesimo, birama ini justru menahan emosi dengan munculnya cressendo dan diakhiri forte pada birama 59 dengan accent. Dapat diperhatikan pada frase ini terdapat permainan dinamik yang seolah membangun suasana pada lagu ini sehingga estetika lagu ini dapat terlihat. Pada birama 60 dan 61 bentuk melodinya hampir sama dengan tema I hanya saja ada penambahan pada ketukan ke 2 dan 4 up beat, dengan posisi mallet 3 dan 4 memukul interval seconde dengan tambahan teknik dead stroke.

Hal yang sama juga terjadi pada mallet 1 dan 2 terdapat gerak 1 oktaf antara mallet 1 dan 2 dan pada tiap ketukan up beat harus memukul dengan interval seconde, jadi ketepatan nada harus diperhatikan pada bagian frase ini. Birama 63-66 posisi mallet 3 dan 4 terdapat dead stroke dengan posisi mallet 1 dan 2 tetap mrlakukan pergerakan oktaf dengan jarak yang pendek. Selanjutnya pada birama 66-69 melodi pada kunci G terdapat sistem buka tutup mallet yang membuat mallet 3 statis tetapi mallet 4 yang bergerak sesuai melodi tersebut. Dinamik pianisimo dan forte membuat melodi terlihat lebih indah dan pada birama 69 posisi mallet 1,2,3 dan 4 terdapat dead stroke, selanjutnya birama 70-72 posisi mallet 1 dan 2 memukul ritmis seperdelapan sedangkan mallet 3 dan 4 memukul ritmis seperenambelas jadi terdapat teknik independent mengharuskan 
pemain lebih fokus lagi pada bagian ini. Birama 73 posisi mallet 1 pada nada Cis, mallet 2 pada nada $C$, mallet 3 pada nada Edan mallet 4 pada nada c1dan juga terdapat tekanan diketukan pertama dengan dinamik fortesimo, dilanjutkan dengan teknik memukulkan tangkai mallet kanan dengan tangkai mallet kiri serta dipantulkan secara alami. Pada ketukan 3 dalam birama ini ada sedikit penahanan tempo untuk menuju ke birama selanjutnya.

\section{Notasi 38 : Birama 74-79}

Pada birama 74 dan 75 terdapat pergerakan posisi mallet yang cukup rumut karena posisi mallet 1 dan 2 pada kunci $F$ bergerak bergantian dengan ritmis seperenambelas dan posisi mallet 3 dan 4 pada kunci $G$ terdepat pergerakan yang sama dengan ditambah tekanan pada ketukan 1,2,3 dan 4 tentu saja ini menambah tingkat kesulitan yang tinggi serta ketelitian bagi pemain. Birama 76 hampir sama dengan birama sebelumnya tetapi untuk posisi mallet pada kunci $G$ terdapat ritmis seperenambelasan tetapi dengan grouping triol, jadi perpaduan antara mallet tangan kiri dan kanan harus stabil tanpa mngurangi kenyamanan pemain dengan berlatih teknik independent pada marimba empat mallet pasti akan dengan mudah melewati bagian tersebut. Pada birama 77-79 memiliki teknik dan posisi mallet yang sama dengan birama sebelumnya dan yang perlu diperhatikan adalah tanda legato disini harus bisa mengendalikan nafas pada tiap frasenya dengan cermat dan teliti.

\section{Notasi 39 : Birama 80-92}

Pada birama $80-81$ bersukat 6/16 artinya pada 1 birama terdapat 6 ketukan dan tiap ketukan bernilai not seperenambelas, terdapat perubahan tempo disini yaitu Lestamente artinya dengan penuh semangat, pada frase ini cenderung lebih tenang tapi tidak mengurangi esensi didalamnya seperti posisi mallet 1 dan 2 pada nada as dan es dan mellet 3 dan 4 pada nada $\mathrm{c}$ dan $\mathrm{g}$. Bagian bilah nada rendah tidak selalu menggunakan posisi mallet 1 dan 2 tetapi pada bagian ini mallet 1 dan 2 cenderung lebih memukul wilayah bilah nada yang rendah. Birama 82 dan 83 posisi mallet sama dengan sebelumnya hanya terdapat pergantian posisi mallet di ketukan 4 dan 5 tiap biramanya, hanya saja posisi mallet tetap bergantian dari kiri dan kanan. Birama 84-85 memiliki kesamaan dengan birama $80-81$ jadi posisi mallet serta teknik yang digunakan hampir sama. Pada birama 86-92 dimulai dengan posisi mallet 3 dan 4 pada ketukan 1 , pada ketukan ke 2 menggunakan mallet 1 dan 2, ini merupakan balikan frase sebelumnya, jika diawal ketukan oleh mallet 1 dan 2 tapi untuk birama ini diawali posisi mallet 3 dan 4 dengan nada $\mathrm{d}$ dan $\mathrm{g}$.

Tanda dinamik piano dan dilanjutkan cresendo besar terdapat pada birama ini dan juga terdapat tekanan/accent yang membuat dinamika pada birama ini naik dan semakin keras. Tentu saja perlu diperhatikan grouping pada frase ini karena terdapat perubahan sukat dari $5 / 8$ menuju $3 / 8$ dan berubah lagi pada sukat 6/16. Birama 93-100 tidak terdapat teknik khusus dalam birama ini, hanya dari posisi mallet saja yang diperhatikan karena prosesnya sama dengan birama 80-91. Pada birama 101-104 hanya terjadi pola bergantian antara mallet kiri dan kanan, dengan adanya subito piano cressendo, pada bagian ini juga perlu memperhatikan dinamik dan gestur tangan karena dimulai dari dinamik piano tentu saja posisi mallet berada dekat dengan bilah dengan posisi tap stroke dan lama kelamaan menjadi full stroke karena dituntut untuk dinamik fortessimo di birama 105. Pada birama 105-108 posisi mallet 1,2,3 dan 4 memukul secara bersama pada ketukan 1 dan memiliki tekanan dengan dinamik fortesimo lalu terdapat cressendo dan 
berakhir di birama 109 dengan dinamik fortesisimo.

\section{Notasi 50 : Birama 109-133}

Pada birama 109-115 diawal birama terdapat aksentuasi dan juga stacato diteruskan dengan decressendo, tentu saja ini mempengaruhi gestur pemain saat menggunakan teknik empat mallet karena posisi mallet 1,2,3 dan 4 dipukul secara bersamaan diketukan 1 , sedangkan mallet 3 dan 4 bergerak naik dan turun dengan membentuk akord dengan jarak interval ters. Teknik independent mallet juga digunakan pada bagian ini dimana mallet pada tangan kiri memainkan ritmis seperdelapan sedangkan mallet pada tangan kanan mamainkan ritmis seperenambelas, tentu saja hal ini menjadi perhatian para pemain agar selalu berkonsentrasi sehingga bagian ini dapat dimainkan dengan benar. Birama 116-132 merupakan alternativ, artinya boleh tidak dimainkan apabila jumlah oktaf pada marimba tidak mencukupi karena dalam lagu ini menggunakan marimba jenis Grand dengan jumlah 5 oktaf. Birama 116-123 mekanisme tekniknya hampir sama dengan birama 60-65, hanya saja pada bagian ini dimulai dari sukat $4 / 8$ jadi grouping melodi serta ritmisnya berbeda dan juga terdapat repetisi tema I yang dikembangkan pada bagian ini seperti birama 116 diketukan 4 sampai birama 117 ketukan ke 4 .

Disini terdapat jarak yang lumayan jauh perpindahan antara mallet 3 dan 4 , yang mana interval second melakukan pergerakan hampir 2 oktaf naik lalu kembali turun pada melodi di kunci G. Posisi mallet 1 dan 2 harus tetap stabil memainkan ritmis seperdelapan dengan perpindahan jarak 1 oktaf, walaupun pada gerak mallet 1 dan 2 terdapat kesulitan karena ketepatan menembak nada selalu tidak tepat, maka dapat digunakan gerakan melompat pada mallet 1 dan 2 walaupun gerakan melompat terkadang membuat mallet tidak stabil karena terlalu banyak bergerak pada pergelangan tangan. Birama 124-132 memiliki kesamaan dengan birama 116-123 jadi posisi mallet serta teknik yang digunakan hampir sama, untuk birama 133 menggunakan posisi mallet secara bergantian antara kanan dan kiri yang diawali dari mallet 1 dengan nada c pada kunci $F$ lalu mallet 3 dan 4 dengan nada e dan f pada kunci G.

\section{Notasi 41 : Birama 137-159}

Pada birama 137-159 merupakan repetisi tema I yang terdapat pada awal bagian lagu ini dan kemudian diulang kembali pada beberapa birama sebelum ending. Tentu saja posisi dan teknik empat mallet pada bagian ini hampir sama dengan bagian awal seperti terdapat teknik dead stroke pada birama 137 dan 138 tiap ketukan ke 2 up beat, terdapat juga tremolo pada birama 139 dan 140 dengan menggunakan teknik one hand roll dengan posisi mallet 3 dan 4 dan posisi mallet 1 dan 2 melakukan teknik dead stroke dengan menggunakan independent roll hingga birama 13 ketukan ke 3. Pada birama 158 dan 159 menggunakan posisi mallet secara bergantian antara kanan dan kiri yang diawali dari mallet 1 dengan nada $C$ pada kunci $F$, selanjutnya mallet 3 dan 4 dengan nada $f$ dan g pada kunci $G$, dan pada birama ini merupaka alternativ notation yang artinya boleh tidak dimainkan apabila jumlah oktaf pada marimba tidak mencukupi untuk memainkan nada tersebut.

\section{Notasi 42 : Birama 160-165}

Pada bagian ini merupakan ending dari lagu Tambourin Paraphrase for Solo Marimba karya Keiko Abe, yang mana terdapat pengulangan introduksi yang terletak pada awal birama, tentu saja pada bagian ini terdapat beberapa teknik seperti dead stroke, shaft mallet dan pada 2 birama 
terkahir yaitu birama 164 terdapat Ritardando/rit yang artinya tempo menurun secara perlahan sampai frase tersebut berakhir di birama 165 ketukan 1 dan terdepat tanda istirahat seperdelapan untuk mengambil nafas dan di akhiri oleh posisi mallet 1,2,3 dan 4 membentuk akord dengan teknik dead stroke. Dalam lagu Tambourin Paraprase for Solo Marimba terdapat beberapa unsur seperti tempo, dinamik dan artikulasi.

Pada bagian introduksi mulai birama 1-9, menggunakan teknik dead stroke dan shaft mallet dimulai pada birama 1 ketukan ke 2 dengan posisi mallet 1 pada nada $F$, mallet 2 pada nada $C$, mallet 3 pada nada $f$ dan mallet 4 pada nada c, kemudian secara bersamaan dipukul dan kepala mallet ditempelkan pada bilah selama setengah ketukan karena terdapat legato dan pada ketukan ke 4, nada $\mathrm{F}$ dan $\mathrm{C}$ dipukul menggunakan mallet 1 dan 2 karena posisinya berada pada bilah nada rendah sama halnya pada birama 2. Pada birama 3 terdapat shaft mallet pada ketukan ke 1,2 dan 4 tetapi sedikit terdapat perbedaan yaitu untuk ketukan 1 dan 2 posisi mallet 1 dan 4 dipukulkan pada ujung bawah bilah dengan menggunakan tangkai mallet. Posisi tangkai mallet harus sejajar dengan arah kepala mallet menghadap posisi 45 derajat dan dipukulkan memanfaatkan kekuatan pantulan secara alami, kemudian untuk ketukan ke 4 posisi mallet sama dengan sebelumnya tetapi hanya dipukul sekali saja dan tidak dipantulkan sama halnya dengan birama 4. Pada birama 4 posisi mallet 1 dan 2 tetap pada kunci $\mathrm{F}$, lalu pada ketukan ke 2 terdapat dead stroke diikuti posisi mallet 3 di nada A. Ritme 1/16 di birama 4 pada kunci G menggunakan posisi mallet 4-3-4-3 karena lebih memungkinkan. Untuk birama 6-9 hanya terdapat pengulangan teknik yang sama dengan sebelumnya.

Notasi 34 : Birama 10-23
Pada birama 10-23 tersebut diatas adalah introduksi frase 1 dan 2 merupakan pengembangan dari introduksi yang tentu saja berhubungan untuk nanti masuk ke tema selanjutnya. Pada birama 10 posisi mallet 1 dan 2 tetap pada posisi bass atau kunci $F$, lalu untuk notasi pada kunci $G$ posisi mallet 3 lebih dominan untuk memainkan melodi tersebut. Pada birama 11 posisi mallet pada kunci G dimulai dari mallet 4-3-4-3-4-43, sedangkan birama 12 ketukan 4 terdapat tremolo/roll dimainkan mallet 3 dan 4 dengan menggunakan teknik one hand roll hingga birama 13 ketukan ke 3, dan disaat yang bersamaan terdapat dead stroke di ketukan ke 2 birama 11 pada mallet 1 dan 2 . Birama 14 samapai 16 posisi mallet 1 dan 2 pada kunci $\mathrm{F}$ dan terdapat dead stroke pada tiap nada ke 2 dan 3, kemudian pada kunci G terdapat ritmis trio'l dengan posisi mallet 44-3 pada tiap triolnya. Sebenarnya untuk kemungkinan dalam pemilihan numbering atau sticking mallet pada lagu ini cukup fleksibel, artinya ketika kita memainkannya dengan penuh keyakinan dan tentu saja mendapatkatkan kenyamanan, itu semua dapat dicari sendiri asalkan tidak bertabrakan antara mallet satu dengan mallet lain. Untuk birama 17sampai 21 posisi mallet pada kunci $G$ lebih menyesuaikan dengan gerak mallet 1 dan 2, karena posisi mallet 3 dan 4 memungkinkan memainkan melodi pada kunci G. Sukat yang selalu berubah dapat menyebabkan gesekan antara mallet tetapi dengan cara mencermati frase demi frase gesekan tersebut dapat terhindari. Pada birama 22 dan 23 dengan sukat 4/8 terdapat dead stroke pada ketukan ke 2 up beat dengan posisi mallet 1-4 dipukul secara bersama dengan dinamik forte lalu pada birama 23 terdapat decressendo yang artinya melembut

\section{Notasi 35 : Birama 24-35}

Selanjutnya pada birama 24-35 merupakan tema I terdapat penahanan 
tempo di birama 24 dan 25. Terdapat dead stroke pada mallet 1 dan 2 dengan nada $F$ dan $\mathrm{C}$ dipukul bersama. Kemudian pada mallet 3 dan 4 memainkan melodi pada kunci G, pada ketukan ke-2 up bead terdapat teknik memukulkan tangkai mallet pada tangan kanan dan kiri sejajar dengan dada. Pada ketukan ke-3 terdapat dead stroke dengan mallet 1, 2, 3, dan 4 memukul nada C D F dan A, selanjutnya birama ke-25 terdapat teknik dengan posisi mallet yang sama. Birama 26 sampai 29 tidak terdapat teknik khusus, melainkan posisi mallet searah berlawanan, mallet 1 dan 2 harus stabil karena banyak presisi pada tiap nada, kemudian untuk mallet 3 dan 4 posisi mallet 3 selalu stabil pada nada $C$ sedangkan mallet 4 yang bergerak naik dan turun. Selanjutnya birama 30 dan 31 mempunyai teknik posisi mallet yang sama yaitu pada birama 24 dan 25 . Pada birama 32 hingga 35 juga mempunyai teknik posisi mallet yang sama dengan birama 26 hingga 29.

\section{Notasi 36 : Birama 36-51}

Birama 36-51 merupakan bagian dari pengembangan tema I, birama 36-41 merupakan alternativ, artinya boleh tidak dimainkan apabila jumlah oktaf pada marimba tidak mencukupi karena sebenarnya dalam lagu Tambourin Paraphrase for Solo Marimba menggunakan marimba jenis Grand dengan jumlah 5 oktaf. Teknik yang dipakai hanya posisi numbering mallet dan sticking yang harus stabil, contoh pada birama 36-37, mallet 1 dan 2 memukul nada $\mathrm{F}$ dan $\mathrm{A}$, sedangkan mallet 4 pada nada $C$ karena mallet 4 merupakan pegangan yang paling kuat ditangan kanan sehingga memudah bermain dengan stabil, hal itu juga berlaku pada birama berikutnya hingga birama 43. Hal tersebut memungkinkan untuk posisi mallet disesuaikan dengan melihat bahwa posisi mallet tersebut mendukung pergerakan pada teknik di dalam lagu ini. Pada birama 44-47 terdapat aksen pada tiap ketukan pertama dengan dinamik forte, pada birama ini sangat kuat tekanan pukulannya walaupun diketukan ke 2 up beat terdapat shaft mallet dan berlanjut dead stroke di ketukan ke 4 .

Pada birama ini memiliki posisi yang sangat sulit karena terdapat tenik shaft mallet dan dead stroke sehingga posisi mallet harus stabil, justru posisi gestur tubuh lah yang sangat membantu dalam menjadikan posisi mallet menjadi stabil. Pada birama selanjutnya yaitu 46 dan 47 terdapat dead stroke dengan posisi mallet agak rumit karena terdapat nada yang naik dengan setengan laras. Selanjutkan teknik memukulkan tangkai mallet antara kanan dan kiri, hal ini perlu ketepatan dalam mengeksekusi posisi mallet dengan nada yang dimainkan. Untuk birama 58-51 memiliki penjelasan yang sama dengan pengulasan sebelumnya, dan intinya ketika mendapatkan teknik yang sulit dalam lagu ini gestur tubuh juga berperan penting dalam mendukung pergerakan posisi mallet 1,2,3 dan 4 sehingga dapat diperoleh hasil suara yang indah.

\section{Notasi 37 : Birama 52-59}

Pada birama 52-59 terdapat pergerakan posisi mallet yang agak rumit, karena melodi pada kunci $G$ posisi mallet 3 dan 4 melakukan sistem buka dan tutup mallet dengan cepat sehingga butuh genggaman yang kuat pada bagian ini agar mallet tidak terlepas dari pegangan pemain. Posisi mallet 1 dan 2 tetap pada kunci F dan terdapat tekanan/accent pada ketukan 1 dan 2 up beat yang membuat pemain harus sedikit emosi pada bagian ini. Adapun pada birama 56 terdapat dinamik piano, berbeda dengan frase sebelumnmya yang menggunakan dinamik fortesimo, birama ini justru menahan emosi dengan munculnya cressendo dan diakhiri forte pada birama 59 
dengan accent. Dapat diperhatikan pada frase ini terdapat permainan dinamik yang seolah membangun suasana pada lagu ini sehingga estetika lagu ini dapat terlihat. Pada birama 60 dan 61 bentuk melodinya hampir sama dengan tema I hanya saja ada penambahan pada ketukan ke 2 dan 4 up beat, dengan posisi mallet 3 dan 4 memukul interval seconde dengan tambahan teknik dead stroke.

Hal yang sama juga terjadi pada mallet 1 dan 2 terdapat gerak 1 oktaf antara mallet 1 dan 2 dan pada tiap ketukan up beat harus memukul dengan interval seconde, jadi ketepatan nada harus diperhatikan pada bagian frase ini. Birama 63-66 posisi mallet 3 dan 4 terdapat dead stroke dengan posisi mallet 1 dan 2 tetap mrlakukan pergerakan oktaf dengan jarak yang pendek. Selanjutnya pada birama 66-69 melodi pada kunci G terdapat sistem buka tutup mallet yang membuat mallet 3 statis tetapi mallet 4 yang bergerak sesuai melodi tersebut. Dinamik pianisimo dan forte membuat melodi terlihat lebih indah dan pada birama 69 posisi mallet 1,2,3 dan 4 terdapat dead stroke, selanjutnya birama 70-72 posisi mallet 1 dan 2 memukul ritmis seperdelapan sedangkan mallet 3 dan 4 memukul ritmis seperenambelas jadi terdapat teknik independent mengharuskan pemain lebih fokus lagi pada bagian ini. Birama 73 posisi mallet 1 pada nada Cis, mallet 2 pada nada $C$, mallet 3 pada nada Edan mallet 4 pada nada c1dan juga terdapat tekanan diketukan pertama dengan dinamik fortesimo, dilanjutkan dengan teknik memukulkan tangkai mallet kanan dengan tangkai mallet kiri serta dipantulkan secara alami. Pada ketukan 3 dalam birama ini ada sedikit penahanan tempo untuk menuju ke birama selanjutnya.

\section{Notasi 38 : Birama 74-79}

Pada birama 74 dan 75 terdapat pergerakan posisi mallet yang cukup rumut karena posisi mallet 1 dan 2 pada kunci $F$ bergerak bergantian dengan ritmis seperenambelas dan posisi mallet 3 dan 4 pada kunci $G$ terdepat pergerakan yang sama dengan ditambah tekanan pada ketukan 1,2,3 dan 4 tentu saja ini menambah tingkat kesulitan yang tinggi serta ketelitian bagi pemain. Birama 76 hampir sama dengan birama sebelumnya tetapi untuk posisi mallet pada kunci $G$ terdapat ritmis seperenambelasan tetapi dengan grouping triol, jadi perpaduan antara mallet tangan kiri dan kanan harus stabil tanpa mngurangi kenyamanan pemain dengan berlatih teknik independent pada marimba empat mallet pasti akan dengan mudah melewati bagian tersebut. Pada birama 77-79 memiliki teknik dan posisi mallet yang sama dengan birama sebelumnya dan yang perlu diperhatikan adalah tanda legato disini harus bisa mengendalikan nafas pada tiap frasenya dengan cermat dan teliti.

\section{Notasi 39 : Birama 80-92}

Pada birama 80-81 bersukat 6/16 artinya pada 1 birama terdapat 6 ketukan dan tiap ketukan bernilai not seperenambelas, terdapat perubahan tempo disini yaitu Lestamente artinya dengan penuh semangat, pada frase ini cenderung lebih tenang tapi tidak mengurangi esensi didalamnya seperti posisi mallet 1 dan 2 pada nada as dan es dan mellet 3 dan 4 pada nada c dan g. Bagian bilah nada rendah tidak selalu menggunakan posisi mallet 1 dan 2 tetapi pada bagian ini mallet 1 dan 2 cenderung lebih memukul wilayah bilah nada yang rendah. Birama 82 dan 83 posisi mallet sama dengan sebelumnya hanya terdapat pergantian posisi mallet di ketukan 4 dan 5 tiap biramanya, hanya saja posisi mallet tetap bergantian dari kiri dan kanan. Birama 84-85 memiliki kesamaan dengan birama $80-81$ jadi posisi mallet serta teknik yang digunakan hampir sama. Pada birama 86-92 dimulai dengan posisi mallet 3 dan 4 pada ketukan 1 , pada ketukan ke 2 menggunakan mallet 1 
dan 2, ini merupakan balikan frase sebelumnya, jika diawal ketukan oleh mallet 1 dan 2 tapi untuk birama ini diawali posisi mallet 3 dan 4 dengan nada d dan $g$.

Tanda dinamik piano dan dilanjutkan cresendo besar terdapat pada birama ini dan juga terdapat tekanan/accent yang membuat dinamika pada birama ini naik dan semakin keras. Tentu saja perlu diperhatikan grouping pada frase ini karena terdapat perubahan sukat dari 5/8 menuju 3/8 dan berubah lagi pada sukat 6/16. Birama 93-100 tidak terdapat teknik khusus dalam birama ini, hanya dari posisi mallet saja yang diperhatikan karena prosesnya sama dengan birama 80-91. Pada birama 101-104 hanya terjadi pola bergantian antara mallet kiri dan kanan, dengan adanya subito piano cressendo, pada bagian ini juga perlu memperhatikan dinamik dan gestur tangan karena dimulai dari dinamik piano tentu saja posisi mallet berada dekat dengan bilah dengan posisi tap stroke dan lama kelamaan menjadi full stroke karena dituntut untuk dinamik fortessimo di birama 105. Pada birama 105-108 posisi mallet 1,2,3 dan 4 memukul secara bersama pada ketukan 1 dan memiliki tekanan dengan dinamik fortesimo lalu terdapat cressendo dan berakhir di birama 109 dengan dinamik fortesisimo.

\section{Notasi 50 : Birama 109-133}

Pada birama 109-115 diawal birama terdapat aksentuasi dan juga stacato diteruskan dengan decressendo, tentu saja ini mempengaruhi gestur pemain saat menggunakan teknik empat mallet karena posisi mallet 1,2,3 dan 4 dipukul secara bersamaan diketukan 1, sedangkan mallet 3 dan 4 bergerak naik dan turun dengan membentuk akord dengan jarak interval ters. Teknik independent mallet juga digunakan pada bagian ini dimana mallet pada tangan kiri memainkan ritmis seperdelapan sedangkan mallet pada tangan kanan mamainkan ritmis seperenambelas, tentu saja hal ini menjadi perhatian para pemain agar selalu berkonsentrasi sehingga bagian ini dapat dimainkan dengan benar. Birama 116-132 merupakan alternativ, artinya boleh tidak dimainkan apabila jumlah oktaf pada marimba tidak mencukupi karena dalam lagu ini menggunakan marimba jenis Grand dengan jumlah 5 oktaf. Birama 116-123 mekanisme tekniknya hampir sama dengan birama 60-65, hanya saja pada bagian ini dimulai dari sukat $4 / 8$ jadi grouping melodi serta ritmisnya berbeda dan juga terdapat repetisi tema I yang dikembangkan pada bagian ini seperti birama 116 diketukan 4 sampai birama 117 ketukan ke 4 .

Disini terdapat jarak yang lumayan jauh perpindahan antara mallet 3 dan 4 , yang mana interval second melakukan pergerakan hampir 2 oktaf naik lalu kembali turun pada melodi di kunci G. Posisi mallet 1 dan 2 harus tetap stabil memainkan ritmis seperdelapan dengan perpindahan jarak 1 oktaf, walaupun pada gerak mallet 1 dan 2 terdapat kesulitan karena ketepatan menembak nada selalu tidak tepat, maka dapat digunakan gerakan melompat pada mallet 1 dan 2 walaupun gerakan melompat terkadang membuat mallet tidak stabil karena terlalu banyak bergerak pada pergelangan tangan. Birama 124-132 memiliki kesamaan dengan birama 116-123 jadi posisi mallet serta teknik yang digunakan hampir sama, untuk birama 133 menggunakan posisi mallet secara bergantian antara kanan dan kiri yang diawali dari mallet 1 dengan nada c pada kunci $F$ lalu mallet 3 dan 4 dengan nada e dan f pada kunci G.

\section{Notasi 41 : Birama 137-159}

Pada birama 137-159 merupakan repetisi tema I yang terdapat pada awal bagian lagu ini dan kemudian diulang kembali pada beberapa birama sebelum 
ending. Tentu saja posisi dan teknik empat mallet pada bagian ini hampir sama dengan bagian awal seperti terdapat teknik dead stroke pada birama 137 dan 138 tiap ketukan ke 2 up beat, terdapat juga tremolo pada birama 139 dan 140 dengan menggunakan teknik one hand roll dengan posisi mallet 3 dan 4 dan posisi mallet 1 dan 2 melakukan teknik dead stroke dengan menggunakan independent roll hingga birama 13 ketukan ke 3. Pada birama 158 dan 159 menggunakan posisi mallet secara bergantian antara kanan dan kiri yang diawali dari mallet 1 dengan nada $C$ pada kunci $F$, selanjutnya mallet 3 dan 4 dengan nada $f$ dan g pada kunci $G$, dan pada birama ini merupaka alternativ notation yang artinya boleh tidak dimainkan apabila jumlah oktaf pada marimba tidak mencukupi untuk memainkan nada tersebut.

\section{Notasi 42 : Birama 160-165}

Pada bagian ini merupakan ending dari lagu Tambourin Paraphrase for Solo Marimba karya Keiko Abe, yang mana terdapat pengulangan introduksi yang terletak pada awal birama, tentu saja pada bagian ini terdapat beberapa teknik seperti dead stroke, shaft mallet dan pada 2 birama terkahir yaitu birama 164 terdapat Ritardando/rit yang artinya tempo menurun secara perlahan sampai frase tersebut berakhir di birama 165 ketukan 1 dan terdepat tanda istirahat seperdelapan untuk mengambil nafas dan di akhiri oleh posisi mallet 1,2,3 dan 4 membentuk akord dengan teknik dead stroke.

\section{Penutup}

Seiring dengan kemajuan jaman, kemampuan dan berbagai pengalaman musikal yang ada pada setiap individu dapat membentuk kehidupannya. Seperti halnya musik perkusi, merupakan hasil imajinasi dan ekspresi pengalaman jiwa manusia. Musik perkusi telah mengalami perkembangan dan perubahan baik dari segi peran, fungsi, pembuatan dan teknik permainannya termasuk salah satunya adalah marimba.

Marimba adalah alat musik pekusi melodis ( definite ) teknik memainkannya dengan cara dipukul yaitu dengan menggunakan stick /mallet. Berbagai macam bentuk, bahan, dan cara pembuatannya, mallet berkali-kali mengalami perubahan hingga akhirnya mencapai titik maksimal sesuai kebutuhan dan fungsinya. Untuk mendapatkan permainan yang lebih berkembang dan menghasilkan suara/nada lebih luas serta komplek, maka dalam memainkan marimba digunakan teknik empat mallet. Dalam memainkan teknik empat mallet banyak hal-hal penting yang harus diperhatikan seperti, bagaimana cara memegang/posisi, membuka dan menutup gerakan mallet dan bagaimana cara memukul.

Sebagai batasan dalam topik ini, maka upaya-upaya pemecahannya dengan cara mengambil sikap, yaitu inti dari skripsi mengarah pada penerapan teknik empat mallet pada lagu Tambourin Paraprase for Solo Marimba karya Keiko Abe. Komposisi musik ini cukup komplek karena menyangkut beberapa teknik yang ada dalam permainan marimba seperti, tradisional roll, independent roll, dead mallet, shaft mallet, arpegio. Teknik penggunaan mallet tersebut dibutuhkan untuk mendukung agar komposisi menjadi lebih hidup sesuai impian komposer. Oleh karena itu, agar membuahkan hasil yang maksimal yang akan mendasari pemahaman estetika musik khususnya perkusi melodis ( marimba ) perlu adanya ketekunan, keseriusan termasuk dalam pemilihan jenis/karakter ( bahan bola dan tangkai mallet ), juga diperlukan latihan secara continue tentu saja tidak lepas dari pengawasan seorang guru, sehingga nantinya akan menghasilkan sebuah permainan marimba yang baik dan benar. 
Teknik permainan musik marimba sudah berkembang pesat, hal itu seiring dengan dinamisasi kemajuan masyarakatnya, terutama sesuai dengan perkembangan pola pikir manusia pada situasi, kondisi dan lingkungan masingmasing. Teknik tersebut menyangkut beberapa hal yaitu penggunaan teknik empat mallet baik independent roll, dead mallet dan shaft mallet, arpegio. Beberapa teknik tersebut merupakan syarat penting yang harus difahami, dimengerti dan dikuasai bagi para pemain marimba, selain untuk mendukung dalam sebuah komposisi juga diharapkan nantinya akan menghasilkan sebuah permainan yang profesional. Hal tersebut perlunya disadari bagi para pemain marimba untuk terus meningkatkan dalam berlatih khususnya penggunaan teknik empat mallet.

\section{Referensi}

Blades,James, Percussion Instruments and Their History, Faber and Faber; London-Boston,1984.

Cirone, J, Anthony. Master Technique Builders Vibraphone and Marimba, Belwin-Mills Publishing Corp, U.S.A. 1985.

Ewen, David, The World of Great Composer, Prentice -Hall.,EngleWoodCliffs, New Jersey, 1962.

Grout, Donald Jae., A History of Western Music, J.M. Dent \& Sons, Limited, London, 1962.

Goldenberg, Morris, Modern School for Xylophone, Marimba, Vibraphone, Chappell \& CO., INC.1950. 